\title{
Modelling climate response to historical land cover change
}

\author{
VICTOR BROVKIN, ANDREY GANOPOLSKI, MARTIN CLAUSSEN, CLAUDIA \\ KUBATZKI and VLADIMIR PETOUKHOV* Potsdam Institute for Climate Impact Research, PO Box \\ 601203, 14412 Potsdam, Germany, E-mail: victor@pik-potsdam.de *Oboukhov Institute for Atmospheric Physics, \\ Pyzhevsky 3, 109017 Moscow, Russia
}

\begin{abstract}
In order to estimate the effect of historical land cover change (deforestation) on climate, we perform a set of experiments with a climate system model of intermediate complexity - CLIMBER-2. We focus on the biophysical effect of the land cover change on climate and do not explicitly account for the biogeochemical effect. A dynamic scenario of deforestation during the last millennium is formulated based on the rates of land conversion to agriculture. The deforestation scenario causes a global cooling of $0.35^{\circ} \mathrm{C}$ with a more notable cooling of the northern hemisphere $\left(0.5^{\circ} \mathrm{C}\right)$. The cooling is most pronounced in the northern middle and high latitudes, especially during the spring season. To compare the effect of deforestation on
\end{abstract}

climate with other forcings, climate responses to the changing atmospheric $\mathrm{CO}_{2}$ concentration and solar irradiance are also analysed. When all three factors are taken into account, dynamics of northern hemisphere temperature during the last 300 years within the model are generally in agreement with the observed (reconstructed) temperature trend. We conclude that the impact of historical land cover changes on climate is comparable with the impact of the other climate forcings and that land cover forcing is important for reproducing historical climate change.

Key words. Modelling, climate change, climate forcing, land cover change, deforestation, solar irradiance, carbon dioxide, land-atmosphere interaction, climate-biosphere interactions.

\section{INTRODUCTION}

During the last millennium, mankind has significantly changed the Earth surface by transforming natural ecosystems (forests and grasslands) into agroecosystems, which mainly consist of croplands, pastures, and bare soil. The changes in vegetation cover should affect the surface albedo and soil hydrology which, in turn, should affect the climate (Dickinson, 1992; Pielke et al., 1998). For the regions that are snow covered in winter, a significant difference in albedo between forest and grassland under snow cover (see, e.g. Dickinson et al., 1993) results in reduced absorbed radiation for the grasslands, especially during the snowthawing season (spring). For these regions, the albedo effect of deforestation on climate is of primary importance. Bonan et al. (1992) showed that, within numerical experiments using National Center for Atmospheric Research (NCAR) climate model CCM1, complete boreal deforestation leads to colder winter and summer temperatures in temperate and high northern latitudes. The cooling was caused in part by oceanic influence, owing to a sea ice-albedo feedback within the model with interactive sea surface temperatures (SST). Thomas \& Rowntree (1992) and Chalita \& Le Treut (1994) in boreal deforestation experiments with atmospheric general circulation models (AGCMs) generally agreed in significant cooling in the spring season within the models and argued that the sharp albedo difference between forest and tundra plays the most significant role in determining the climate-vegetation state of the region. Bonan (1997), in experiments with the modified CCM2 model with prescribed SST, obtained a significant summer cooling effect of land cover changes on the climate of the USA. Betts (1999), using the Hadley Centre climate model HadCM3 with prescribed SST, showed that historical land cover change results in a 


\section{$510 \quad$ V. Brovkin et al.}

reduction in mid-latitude annual mean temperatures within the model. The hydrological effect of the deforestation should be quite important in the tropical and subtropical regions (Zhang et al., 1997; Zheng \& Eltahir, 1997). However, while the albedo effect could be modelled properly, the hydrological effect of deforestation is less certain, especially on a global scale (Rind, 1996).

Deforestation alters the terrestrial carbon budget, because biomass in grasslands has a faster turnover time in comparison with forests. The release of carbon into the atmosphere owing to historical land cover change is quite significant. For example, carbon emission due to land cover change for the years 1860-1980 was estimated to have been $180 \mathrm{Gt}(\mathrm{Gt}=$ $10^{15} \mathrm{~g}$ ) by Houghton et al. (1983). A numerical experiment with the Lund-Potsdam-Jena vegetation model resulted in emission of $145 \mathrm{Gt}$ of carbon associated with land cover changes for the years 1860-1995 (Stephen Sitch, personal communication). The carbon dioxide emission leads to increasing atmospheric $\mathrm{CO}_{2}$ concentration and, consequently, global warming. However, a calculation of changes of atmospheric $\mathrm{CO}_{2}$ concentration owing to land cover change requires the simulation of transient carbon uptake by the ocean. At present, a model of ocean biogeochemistry is not included within our climate system model. Therefore, we focus here on the biogeophysical effect of the deforestation on climate and do not directly account for the biogeochemical effect. The latter is implicitly taken into account in our experiments with the climate system forced by the historical trend of atmospheric $\mathrm{CO}_{2}$ concentration.

Land cover change is a long-term process, which started with the first human settlements, which grew in conjunction with population density, and which has accelerated over the last century. There is a growing interest in the role that historical land cover change could play in climate change. For example, one can hypothesize that observed patterns of climate anomalies in the northern hemisphere during the 16-19th centuries (the 'Little Ice Age') could partly be explained by the deforestation of a significant part of Europe and North America. However, performing multicentury long simulations with AGCMs is very expensive, and reliable data about deforestation before the 17 th century are very rare. Therefore, at present, it is only possible to analyse general features of land use change impacts on climate. Here we apply a coarse resolution model of climate to a deforestation scenario in order to obtain a qualitative first approximation of the role of land cover change in historical climate change.

\section{METHODS}

\section{The model}

We performed a set of experiments with a climate system model of intermediate complexity - CLIMBER2 (Ganopolski et al., 1998a; Petoukhov et al., 1999). The model has a course resolution of $10^{\circ}$ in latitude and $51^{\circ}$ in longitude. It includes a 2.5-dimensional dynamical-statistical atmosphere model; a multibasin, zonally averaged ocean model including a sea ice model; and a terrestrial vegetation model VECODE. CLIMBER-2 does not employ any flux adjustment between the atmospheric and oceanic modules. The model climate sensitivity to a doubling of atmosphere $\mathrm{CO}_{2}$ concentration is $2.6^{\circ} \mathrm{C}$, which is in the middle of the range given by the IPCC (Kattenberg et al., 1996).

The vegetation module VECODE is based on a continuous bioclimatic classification (Brovkin et al., 1997). Vegetation is described as a mixture of plant functional types (trees and grasses only). The equilibrium vegetation cover was estimated from annual climate parameters (precipitation, temperature, growing degree-days). If the climate changes, the model simulates vegetation transition from the equilibrium for the previous climate towards an equilibrium for the new climate. The time scale of this transition is determined from the model of the carbon cycle. Tree and grass fractions and maxima of leaf area index (LAI), simulated with an annual time step within the vegetation model, are accounted for in the atmospheric model. Heat, water, and momentum fluxes between surface and atmosphere are calculated for every time step of the atmospheric model (one day) separately for each surface type (forest, grassland, bare soil, water) and then summed up linearly according to the fractions of the surface types within one grid box. A surface parameterization scheme is based on the biosphereatmosphere transfer scheme BATS (Dickinson et al., 1993). Surface albedo depends on LAI, relative soil moisture, snow cover, as well as on snow age. Surface roughness, prescribed for every surface type, determines effective wind speed, sensible heat flux, and evaporation. Evapotranspiration is simulated accounting for LAI, leaf water-holding ability, leaf conductance, root resistance, stomatal resistance, and 
Land cover impact on climate $5 \mathrm{II}$

soil moisture. Soil moisture budget, in turn, is determined by precipitation, evaporation, interception, snow melting, actual transpiration, and drainage.

In CLIMBER-2, the vegetation model is coupled to the climate model without corrections for climate model biases as we believe this is necessary for appropriate study of feedbacks within the climate system. The same approach is used, for example, by Foley et al., (1998) within the climate system model GENESIS-IBIS. CLIMBER-2 is able to simulate the basic global patterns of vegetation cover for present-day climate. Several sensitivity experiments undertaken with CLIMBER-2 have showed reasonable changes of vegetation cover for past climates. For example, when the insolation forcing is changed to mid-Holocene conditions (some 6000 years ago), the changes in vegetation cover in the high northern latitudes and North Africa within the model are in agreement with palaeobotanic data (Ganopolski et al., 1998b). Moreover, these experiments confirmed that changes in vegetation cover can significantly enhance the effect of changed external forcing (e.g. insolation, atmospheric $\mathrm{CO}_{2}$ concentration) on climate.

Preliminary study of the effect of deforestation on climate within the CLIMBER-2 model has indicated the importance of albedo changes in the regions that are snow covered in winter. Here deforestation leads to cooling of surface air, especially in spring. In the regions that are permanently free from snow cover, the changes of surface albedo due to deforestation are not significant and the main effect of deforestation originates in changes in the hydrological cycle. During the growing season, grassland transpires less water than forest within the model. Therefore, deforestation leads to decreased latent heat flux and increased surface air temperatures. If SST values in the model are fixed, as in the majority of deforestation experiments discussed in the Introduction, the tropical deforestation within CLIMBER-2 results in an increase of surface air temperature and a decrease of precipitation over the land. However, if SST values are interactive, the warming over the land is mitigated by the decrease of SST values in the tropics. The latter is the result of a decrease of atmospheric water vapour (major greenhouse gas) due to the reduction of evapotranspiration from the deforested land. Thus the tropical deforestation experiment with CLIMBER-2 with interactive SST shows a decrease of global surface air temperature, while the same experiment with fixed SST results in an increase of the global surface air temperature within the model. This difference is caused by the absence of feedbacks between the ocean and the atmosphere in the case of fixed SST. We conclude that one has to be cautious in interpreting results of experiments with deforestation of low latitude regions simulated by AGCMs with fixed SST values. Note that the interactive ocean model is used for experiments described in this paper.

Here we show the consequences of deforestation on climate, relative to two other climate forcings: $\mathrm{CO}_{2}$ concentration in the atmosphere and solar irradiance. Geographically and temporary explicit historical trends of sulphur aerosol emissions, as well as their direct and indirect climate effects, are each rather uncertain (Rind, 1996; Schimel et al., 1996), and therefore we do not take aerosols into account.

\section{Control run}

The equilibrium climate has been simulated during an 8000 -year run of the coupled atmosphere, ocean, and vegetation models. Solar irradiance and $\mathrm{CO}_{2}$ concentration have been fixed to $1365 \mathrm{~W} / \mathrm{m}^{2}$ and 280 p.p.m., respectively. The present-day orbital parameters have been used. As a result, the potential tree fraction, averaged over the land except Antarctica, is approximately $0.4\left(54 \times 10^{6} \mathrm{~km}^{2}\right)$.

\section{Scenarios}

\section{Deforestation scenario (D)}

By land cover change we mean deforestation, as crop and pasture ecosystems are similar to grasslands in respect to those characteristics which affect heat balance, hydrological and carbon cycles. Because of the small scale of historical conversion of forest ecosystems to agriculture in the high latitude regions, we neglect deforestation in latitudes higher than $60^{\circ} \mathrm{N}$, and in the belt $50^{\circ}-60^{\circ} \mathrm{N}$, excluding Eurasia west of $90^{\circ} \mathrm{E}$. Actual tree fraction for areas affected by deforestation is obtained from the CARAIB model (Pierre Warnant, personal communication), which, in turn, is based on the Wilson \& Henderson-Sellers (1985) land cover data set with specified tree fraction for each land cover type. In some land cells, the actual tree fraction obtained from CARAIB was higher than the potential tree fraction in CLIMBER-2. In these grid cells, the actual tree fraction $f_{1}$ was chosen to be equal to the potential fraction $f_{0}$. As a result, the actual tree fraction, averaged over the land except Antarctica, is approximately $0.25\left(34 \times 10^{6} \mathrm{~km}^{2}\right)$. 


\section{V. Brovkin et al.}

A hypothetical dynamic scenario of deforestation in the past is based on the rates of land conversion to agriculture estimated by Houghton et al. (1983). At the beginning (year $1000 \mathrm{AD}$.) the tree fraction $f$ is equal to the potential tree fraction $f_{0}$, and in the year 1990 it is equal to the actual tree fraction $f_{1}$. Between the years 1000 and 1990 , the tree fraction $f(t)$ is equal to:

$$
f_{0}-\left(f_{0}-f_{1}\right) \cdot r(t) / \int_{1000}^{1990} r(\mathrm{t}) d t
$$

where $t$ is time and $r(t)$ is a land conversion rate for the given land cell estimated from Appendix 5 of Houghton et al. (1983). Before 1700, the deforestation areas in the scenario are limited to Europe, China, and South Asia. For these regions, we assume that during the years 1000-1700 the deforested areas have been linearly increased from zero to the values based on the estimation of agricultural areas in $1700 \mathrm{AD}$. from Appendix 5 of Houghton et al. (1983). In Fig. 1(A) the scenario is shown in terms of zonally averaged change in tree fraction $f(t)-f_{0}$.

Land cells that are affected by deforestation have prescribed tree fraction $f(t)$ within the model, while grass and desert fractions are changed interactively with climate change. In land cells in the high northern latitudes, deforestation is neglected and the tree fraction is changed interactively with climate. This modifies the climate through climate-vegetation feedbacks. For example, vegetation-snow-albedo feedback is important in the high northern latitudes, where a decreased temperature leads to a retreating tree line to the south and an increased albedo during the snowcovered period, which, in turn, leads to an additional temperature decrease (see, e.g. Ganopolski et al., 1998b; Levis et al., 1999).

\section{$\mathrm{CO}_{2}$ scenario $(\mathrm{C})$}

During the years 1000-1800, the atmospheric $\mathrm{CO}_{2}$ concentration is fixed at a constant level $(280 \mathrm{ppm})$. The trend of $\mathrm{CO}_{2}$ for the period 1800-1992 is taken from Neftel et al. (1993) and Keeling (1993) (see Fig. 1B).

\section{Solar irradiance scenario (S)}

We do not account for changes in solar insolation before 1630 . During the years $1000-1630$, the solar irradiance is fixed at $1365 \mathrm{~W} / \mathrm{m}^{2}$. Between 1630 and 1650 , solar irradiance is assumed to decrease linearly to $1361.4 \mathrm{~W} / \mathrm{m}^{2}$ in accordance with Cubasch et al.
(1997). The irradiance is taken to be constant during the years $1650-1700$ (the Maunder minimum). From the year 1700, the dynamics of solar irradiance is prescribed following the estimates by Hoyt \& Schatten (1993), which have been normalized to an average value of $1365 \mathrm{~W} / \mathrm{m}^{2}$ by Cubasch et al. (1997) (see Fig. 1C).

The CLIMBER-2 model has been run using scenarios (D) (C), and (S) in order to determine the effect of every forcing on the climate separately. Additionally, a model simulation with the combination of all three factors (DCS) has been made. In all scenarios, the equilibrium climate from the control run has been taken as the initial conditions in the year $1000 \mathrm{AD}$.

\section{RESULTS}

\section{Climate change for the years 1000-1990}

In terms of mean annual air temperature averaged over the last decade of the simulation (1981-90), the deforestation scenario (D) results in a global cooling of $0.35^{\circ} \mathrm{C}$, with a more notable cooling over the northern hemisphere of $0.5^{\circ} \mathrm{C}$. It is shown in Fig. 2(A) that the air temperature in this experiment decreased monotonically with a maximum rate during the first half of the 20th century. The mean annual temperature decreases significantly over continents in temperate and high latitudes with a maximum cooling of $1.3^{\circ} \mathrm{C}$ over Siberia (Fig. 3A). In terms of seasonal changes of land surface temperature, a maximum cooling of $1.5^{\circ} \mathrm{C}$ occurs in the northern temperate and high latitudes during the spring snow melt (see Fig. 4A), when the vegetation-snow-albedo feedback is most notable. This result is in agreement with Bonan et al. (1992). Owing to deforestation, land areas in latitudes $30^{\circ}-50^{\circ} \mathrm{N}$ are approximately $0.5^{\circ} \mathrm{C}$ and $1{ }^{\circ} \mathrm{C}$ cooler in winter and summer seasons, respectively. Arctic sea ice area increases, which in turn amplifies the decrease of temperature through the sea ice-albedo feedback. Cooling of the southern hemisphere $\left(0.2^{\circ} \mathrm{C}\right)$ is a combined result of tropical deforestation and changes in atmospheric and oceanic meridional transport of energy. The tropical and subtropical regions are slightly drier (Fig. 3B). In the Sahel region of North Africa $\left(10^{\circ}-20^{\circ} \mathrm{N}\right.$ ), the desert fraction increases by $10 \%$ (not shown) as a consequence of the vegetation response to increased aridity.

The $\mathrm{CO}_{2}$ scenario $(\mathrm{C})$ leads to a global warming of $0.5^{\circ} \mathrm{C}$ for the decade $1981-90\left(0.6^{\circ} \mathrm{C}\right.$ for the northern 
$\mathbf{A}$

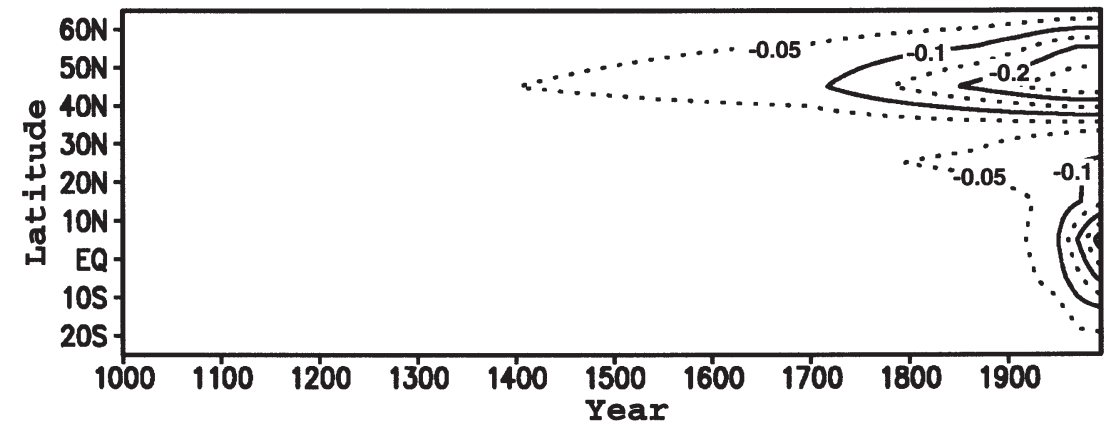

B

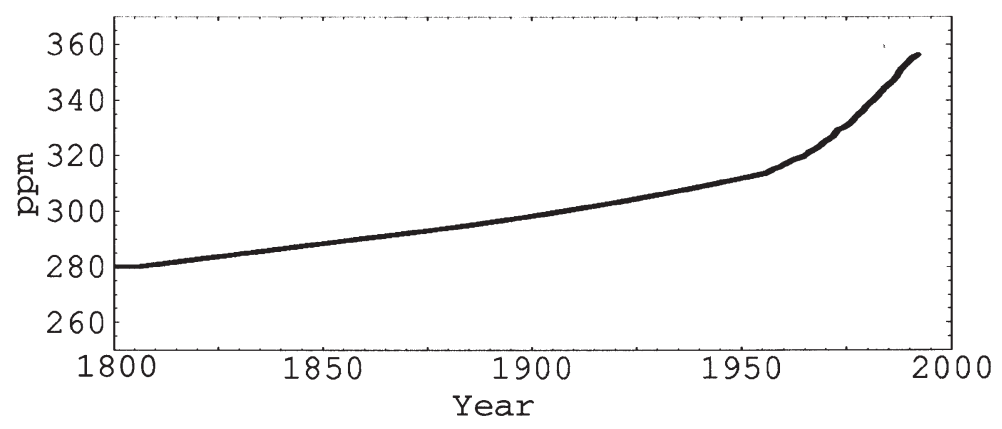

C

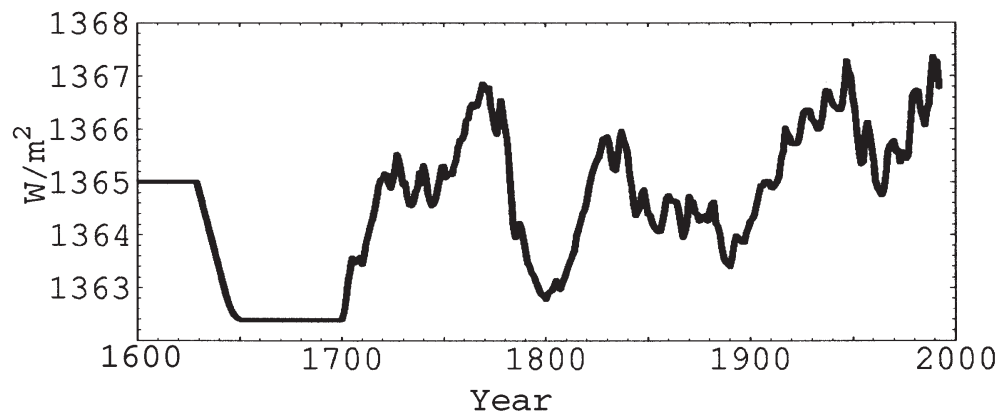

Fig. I. Dynamics of climate forcings used in the simulations. A) Zonally averaged changes in the tree fraction (see explanation of deforestation scenario in the text). The thick contour lines are for levels of $-0.1,-0.2,-0.3$, and the dotted contour lines are for levels of $-0.05,-0.15,-0.25$; B) $\mathrm{CO}_{2}$ concentration in the atmosphere (Keeling, 1993; Neftel et al., 1993); C) Solar irradiance (Cubasch et al., 1997).

hemisphere, see Fig. 2A). The warming is notable in all regions with a maximum in the northern high latitudes. Precipitation increases slightly in the tropical regions and monsoon regions in Asia (not shown).

The solar irradiance scenario (S) results in temperature fluctuations around the mean temperature
(Fig. 2A). Obviously, as irradiance is the only energy source for the system, the temperature changes follow the irradiance changes. Northern hemisphere cooling of $0.25^{\circ} \mathrm{C}$ in the second half of the 17 th century (see Fig. 2A) is caused by the Maunder minimum in insolation. The solar irradiance is higher during the 
A

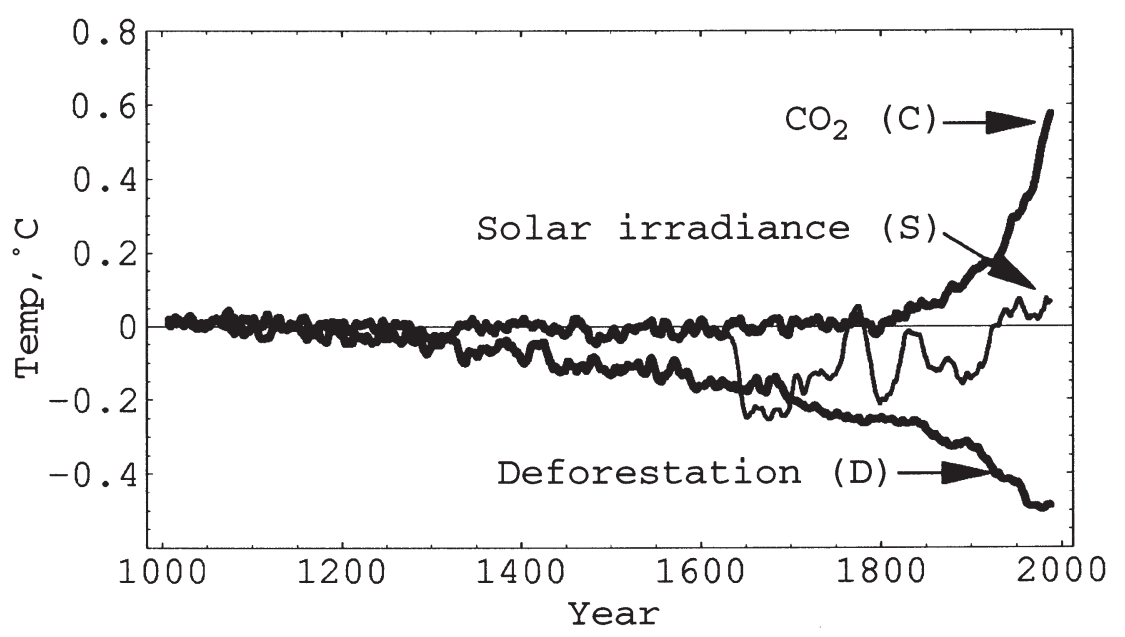

B

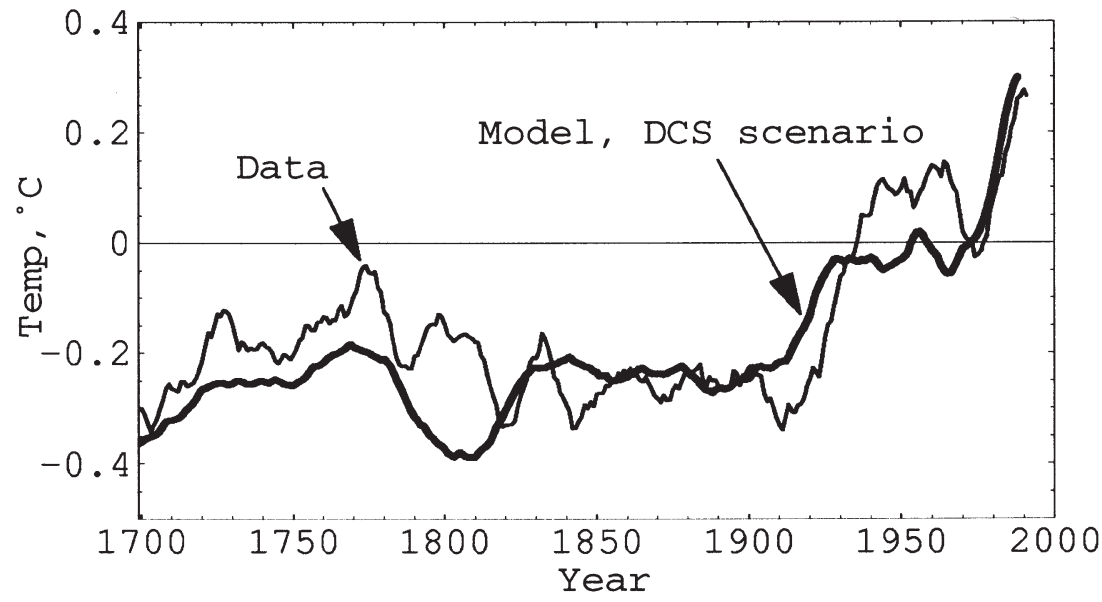

Fig. 2. Dynamics of the mean annual air temperature $\left(\right.$ in ${ }^{\circ} \mathrm{C}$ ) for the northern hemisphere relative to the initial conditions. Data are smoothed with the 10-years moving average. A) Results for D, C, and S scenarios; B) Results for DCS scenario are shown against the reconstructed data (Mann et al., 1998). The latter have been shifted so that their averages and DCS averages are equal for the reference period 1902-1980.

last decades of the 20th century (Fig. 1B), resulting in temperature increase of $0.1{ }^{\circ} \mathrm{C}$ in the northern hemisphere for the decade 1981-90.

Temporal changes in zonally averaged temperature for the DCS scenario are shown in Fig. 5. On a global scale, the DCS scenario results in a warming of $0.3^{\circ} \mathrm{C}$ $\left(0.3^{\circ} \mathrm{C}\right.$ for the northern hemisphere as well). During the years 1000-1630, when the changes in insolation are not accounted for in the scenario, the increasing cooling in the northern high and temperate latitudes is clearly visible in Fig. 5. The Maunder minimum in insolation results in a global cooling during the years 1630-1720 within the model. After 1720, the temperature dynamics are returned to the previous trend due to deforestation until the next cold event caused by an insolation minimum around the year 
A

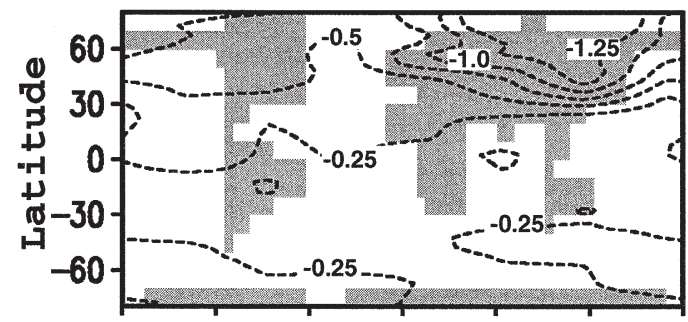

C

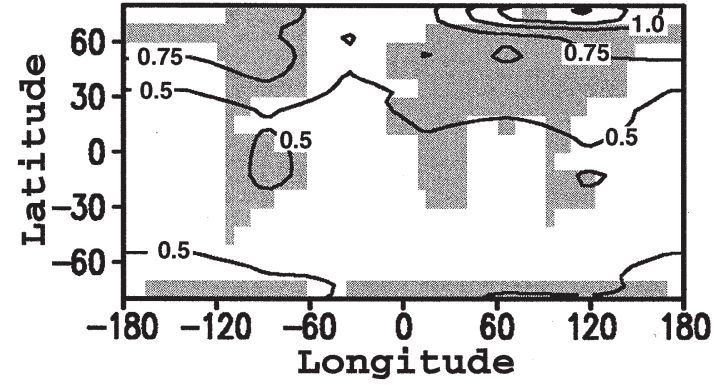

B

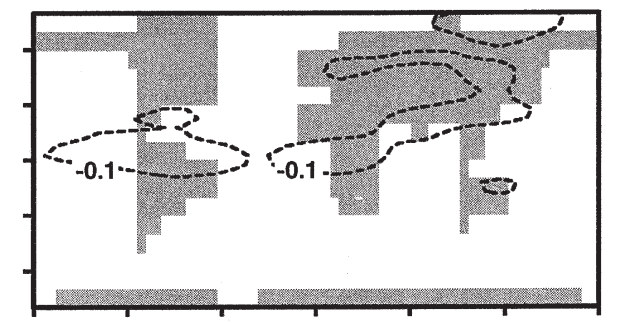

D

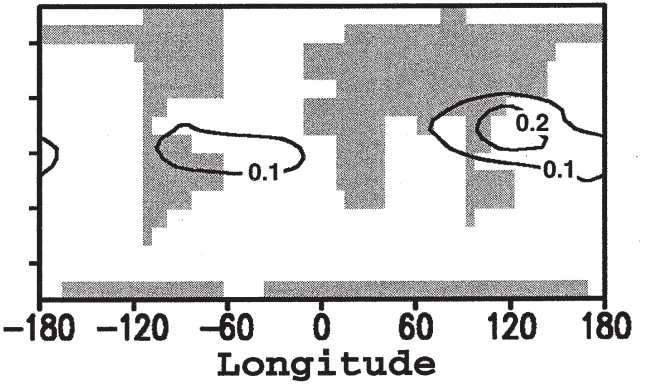

Fig. 3. Difference in the mean annual air temperature (in ${ }^{\circ} \mathrm{C}$ ) between decade $1981-90$ and the initial conditions for deforestation scenario D (A), and between decade 1981-1990 and decade 1891-1900 for combined forcings scenario DCS (C). (B) and (D) are the same as (A) and (C), respectively, but for precipitation (in $\mathrm{mm} /$ day). Dashed lines indicate negative differences. Contour intervals are $0.25{ }^{\circ} \mathrm{C}$ and $0.1 \mathrm{~mm} /$ day for temperature and precipitation, respectively.

1800. During the second half of the 19th century, the temperature within the model is fairy constant, as a warming effect due to a growing atmospheric $\mathrm{CO}_{2}$ concentration is compensated by the cooling effect of deforestation. In the 20th century, the fast growth of atmospheric $\mathrm{CO}_{2}$ concentration causes a rapid warming, especially in the northern hemisphere. The modelled spatial patterns of climate change during the 20th century are presented in Fig. 3. Mean annual temperature increases by more than $0.3^{\circ} \mathrm{C}$ everywhere with a maximum in the northern high latitudes (up to $1{ }^{\circ} \mathrm{C}$ over the Arctic coast of Eurasia and North America). Precipitation increases slightly in the tropical regions and monsoon regions in south-eastern Asia (see Fig. 3D). The warming is more notable during the winter season (Fig. 4B). In the spring season, the potential $\mathrm{CO}_{2}$ warming is damped by cooling due to the impact of deforestation.

\section{Comparison against observation for the years $1700-1990$}

In Fig. 2(A) the trend of annual surface air temperature averaged over the northern hemisphere for the years
1700-1990 is shown against the reconstructed data (Mann et al. 98), which have been adapted for comparison (decreased by $0.04{ }^{\circ} \mathrm{C}$ in order to equalize their averages and DCS averages for the reference period 1902-80). Generally, the temperature increase during the study period within the model is similar to the observed pattern. During the years 1700-1780, the variations in modelled temperature follow the variations of reconstructed temperature. The main factor responsible for temperature variability in the model during this time is the solar irradiance. During the years around 1800 , the model predicts a cooling (in accordance with a minimum in solar irradiance), and observations show a warming. Therefore, the other climate forcings could be responsible for the warming during this period. During the second half of the 19th century, the temperature is stabilized in the model because the cooling effect of the deforestation roughly equals the warming effect of the growing $\mathrm{CO}_{2}$ concentration in the atmosphere. From about 1900, $\mathrm{CO}_{2}$ becomes the dominating climate-forcing in the model. During the period 1900-90, its warming effect is $0.5^{\circ} \mathrm{C}$, while increased solar irradiance results in $0.2{ }^{\circ} \mathrm{C}$, and the deforestation effect is $-0.2^{\circ} \mathrm{C}$. During 


\section{V. Brovkin et al.}
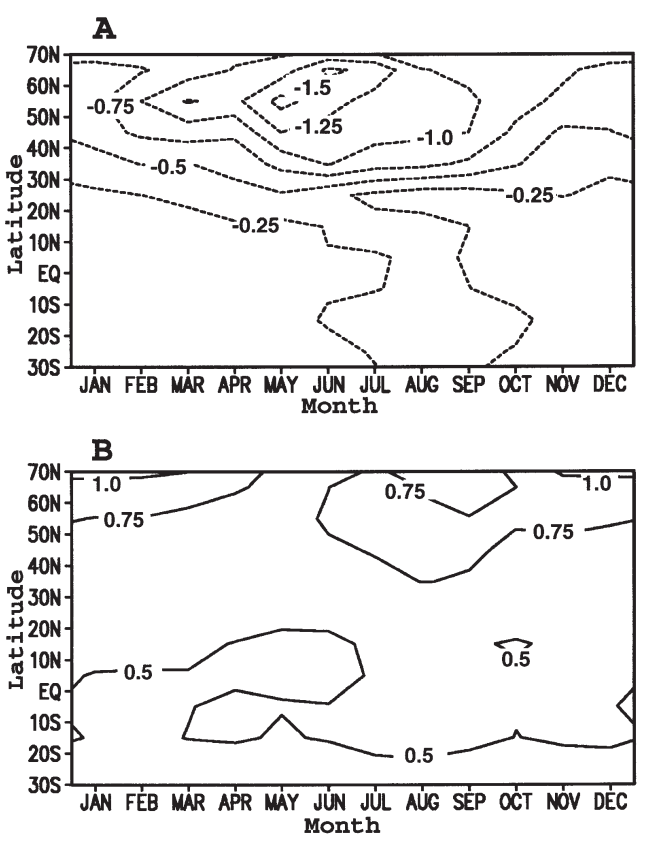

Fig. 4. Seasonal difference in air temperature, zonally averaged over the land surface for the northern hemisphere, between decade 1981-1990 and initial conditions for deforestation scenario D (A), and between decade 1981-1990 and decade 1891-1900 for combined forcings scenario DCS (B). Dashed lines indicate negative differences. The contour interval is $0.25^{\circ} \mathrm{C}$. the 20th century, the warming of the northern hemisphere is $0.55^{\circ} \mathrm{C}$ within the model as compared with $0.5^{\circ} \mathrm{C}$ for the observations.

\section{CONCLUSIONS}

Experiments with the coupled atmosphere-oceanvegetation model CLIMBER-2 indicate that historical land cover change leads to a cooling of the Earth's surface in comparison with natural land cover. The cooling is notable on the global scale, and is more pronounced in the high and temperate latitudes of the northern hemisphere. In terms of seasonal changes, the maximum cooling in the high northern latitudes occurs in the spring season, emphasizing the significance of the albedo effect. Again, note the biogeochemical effect of deforestation (warming due to released carbon to the atmosphere) is not taken into account.

In comparison with the other studied radiative forcings, deforestation is of the same order of magnitude as $\mathrm{CO}_{2}$ and solar irradiation, although the relative importance of the forcings varies with time. Our model results suggest that until the 19th century, variability in solar irradiance was the major forcing responsible for the climate variability, while a cooling effect of deforestation was growing monotonically. Later, the increasing deforestation rate contributed to a stabilization of the temperature during the second half of the 19th century, and has damped the $\mathrm{CO}_{2}$ warming in the 20 th century.

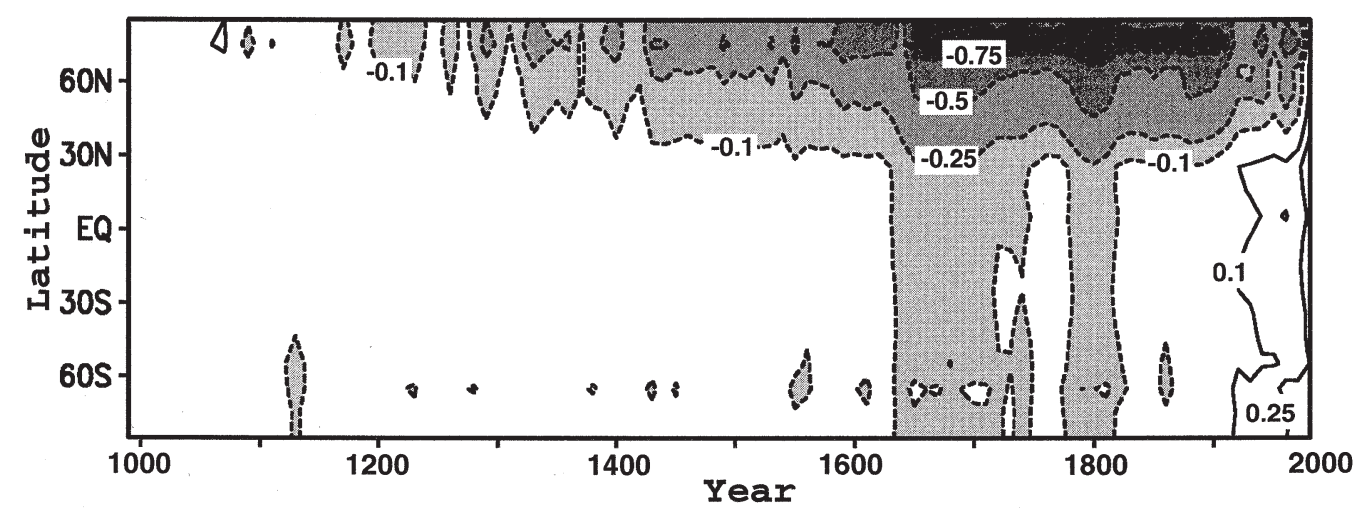

Fig. 5. Dynamics of the zonally averaged mean annual air temperature relative to the initial conditions for combined forcings scenario DCS. Data are averaged over 10 years. Contour levels (in ${ }^{\circ} \mathrm{C}$ ) are $-0.75,-0.5,-0.25,-0.1,+0.1,+0.25$. Shading and dashed lines indicate negative differences. 


\section{ACKNOWLEDGMENTS}

The authors thank Stephen Sitch and two anonymous reviewers for their helpful comments on the paper.

\section{REFERENCES}

Betts, R.A. (1999) The impact of land use on the climate of present day. In: Research Activities in Atmospheric and Oceanic Modelling (ed. by H. Ritchie). CAS/JSC WGNE Report no. 28, pp. 7.11-7.12, World Meteorological Organization, Geneva.

Bonan, G.B., Pollard, D. \& Thompson, S.L. (1992) Effects of boreal forest vegetation on global climate. Nature, 359, 716-718.

Bonan, G.B. (1997) Effects of land use on the climate of the United States. Climatic Change, 37, 449-486.

Brovkin, V., Ganopolski, A. \& Svirezhev, Y. (1997) A continuous climate-vegetation classification for use in climate-biosphere studies. Ecological Modelling, 101, 251-261.

Chalita, S. \& Le Treut, H. (1994) The albedo of temperate and boreal forest and the Northern Hemisphere climate: a sensitivity experiment using the LMD GCM. Climate Dynamics, 10, 231-240.

Cubasch, U., Voss, R., Hegerl, G.C., Waszkewitz, J. \& Crowley, T.J. (1997) Simulation of the influence of solar radiation variations on the global climate with an ocean-atmosphere general circulation model. Climate Dynamics, 13, 757-767.

Dickinson, R.E., Henderson-Sellers, A. \& Kennedy, P.J. (1993) Biosphere-atmosphere transfer scheme (BATS), Version 1e, as coupled to the NCAR community climate model, pp. 72. NCAR Technical Note TN-387+STR, Boulder, Colorado.

Dickinson, R.E. (1992) Changes in land-use. Climate System Modelling (ed. by K.E. Trenberth), pp. 689-700. Cambridge University of Press, Cambridge.

Foley, J.A., Levis, S., Prentice, I.C., Pollard, D. \& Thompson, S.L. (1998). Coupling dynamic models of climate and vegetation. Global Change Biology, 4, 561-579.

Ganopolski, A., Rahmstorf, S., Petoukhov, V. \& Claussen, M. (1998a) Simulation of modern and glacial climates with a coupled model of intermediate complexity. Nature, 391, 351-353.

Ganopolski, A., Kubatzki, C., Claussen, M., Brovkin, V. \& Petoukhov, V. (1998b) The influence of vegetation-atmosphere-ocean interaction on climate during the mid-Holocene. Science, 280, 1916-1919.

Houghton, R.A., Hobbie, J.E., Melillo, J.M., Moore, B., Peterson, B.J., Shaver, G.R. \& Woodwell, G.M. (1982) Changes in the carbon content of terrestrial biota and soils between 1860 and 1980: a net release of $\mathrm{CO}_{2}$ to the atmosphere. Ecological Monographs, 53, 235-262.

Hoyt, D. \& Schatten, K.H. (1993) A discussion of plausible solar irradiance variations, 1700-1992. Journal of Geophysical Research, 98, 18895-18906.

Kattenberg, A. et al. (1996) Climate models - projections of future climate. Climate Change 1995: the Science of Climate Change (ed. by J.T. Houghton, et al.), pp. 285-358. Cambridge University of Press, Cambridge.

Keeling, C.D. (1993) Atmospheric $\mathrm{CO}_{2}$ Concentrations Mauna Loa Observatory, Hawaii, 1958-93. NDP-001. Carbon Dioxide Information Analysis Center, Oak Ridge National Laboratory, Oak Ridge, Tennessee.

Levis, S., Foley, J.A., Brovkin, V. \& Pollard, D. (1999) On the stability of the high-latitude climate-vegetation system in a coupled atmosphere-biosphere model. Global Ecology and Biogeography, 8, 489-500.

Mann, M.E., Bradley, R.S. \& Hughes, M.K. (1998) Globalscale temperature patterns and climate forcing over the past six centuries. Nature, 392, 779-787.

Neftel, A., Friedli, H., Moor, E., et al. (1993) Atmospheric carbon dioxide concentration - historical record. Siple Station, Trends '93: a Compendium of Data on Global Change. Carbon Dioxide Information Analysis Center, Oak Ridge National Laboratory, Oak Ridge, Tennessee.

Pielke, R.A., Avissar, R., Raupach, M., Dolman, A.J., Zeng, X. \& Denning, A.S. (1998) Interaction between the atmosphere and terrestrial ecosystems: influence on weather and climate, Global Change Biology, 4, 461-475.

Petoukhov, V., Ganopolski, A., Brovkin, V., Claussen, M., Eliseev, A., Kubatzki, C. \& Rahmstorf, S. (1999) CLIMBER-2: a climate system model of intermediate complexity. Part I: Model description and performance for present climate. Climate Dynamics, in press.

Rind, D. (1996) The potential for modeling the effects of different forcing factors on climate during the past 2000 years. Climate Variations and Forcing Mechanisms of the Last 2000 Years (ed. by P.D. Jones, R.S. Bradley \& J. Jouzel), pp. 563-581. Springer, Berlin.

Schimel, D. et al. (1996) Radiative forcing of climate change. Climate Change 1995: the Science of Climate Change (ed. by J.T. Houghton, et al.), pp. 65-132. Cambridge University Press, Cambridge.

Thomas, G. \& Rowntree, P.R. (1992) The boreal forest and climate. Quarterly Journal of the Royal Meteorological Society, 118, 469-497.

Wilson, M.F. \& Henderson-Sellers, A. (1985) A global archive of land cover and soils data for use in general circulation models. Journal of Climate, 5, 119-143.

Zhang, H., Henderson-Sellers, A. \& McGuffie, K. (1997) Impacts of tropical deforestation. Part II: The role of large scale dynamics. Journal of Climate, 10, 2498-2521.

Zheng, X. \& Eltahir, E.A.B. (1997) The response to deforestation and desertification in a model of West African monsoons. Geophysical Research Letters, 24, $155-158$. 